\title{
Socioeconomic determinants of psychotropic drug utilisation among elderly: a national population-based cross-sectional study
}

\author{
Eva Lesén*1, Karolina Andersson'1, Max Petzold ${ }^{1}$ and Anders Carlsten 1,2
}

\begin{abstract}
Background: Psychotropic drugs are commonly utilised among the elderly. This study aimed to analyse whether two socioeconomic determinants - income and marital status - are associated with differences in utilisation of psychotropic drugs and potentially inappropriate psychotropic drugs among elderly in Sweden.

Methods: All individuals aged 75 years and older who had purchased a psychotropic drug in Sweden during 2006 were included (68.7\% women, $n=384712$ ). Data was collected from national individual-based registers. Outcome measures were utilisation of three or more psychotropic drugs and utilisation of potentially inappropriate psychotropic drugs, as classified by the Swedish National Board of Health and Welfare.

Results: Individuals with low income were more likely to utilise three or more psychotropic drugs compared to those with high income; adjusted odds ratio (aOR) 1.12 (95\% confidence interval [CI] 1.10-1.14). The non-married had a higher probability for utilising three or more psychotropic drugs compared to the married (aOR 1.22; $\mathrm{Cl} 1.20-1.25$ ). The highest probability was observed among the divorced and the never married. Potentially inappropriate psychotropic drugs were more common among individuals with low compared to high income (aOR 1.14; Cl 1.13-1.16). Compared to the married, potentially inappropriate psychotropic drug utilisation occurred more commonly among the nonmarried (aOR 1.08; $\mathrm{Cl}$ 1.06-1.10). The never married and the divorced had the highest probability.

Conclusions: There was an association between socioeconomic determinants and psychotropic drug utilisation. The probability for utilising potentially inappropriate psychotropics was higher among individuals with low income and among the non-married.
\end{abstract}

\section{Background}

Psychotropic drugs are common among the elderly and represent a considerable proportion of inappropriate drugs used in this population [1]. The elderly are especially vulnerable to drug-related adverse health outcomes, and exposure to inappropriate drugs is associated with an increased risk of such events [2]. Socioeconomic determinants (e.g., poverty and lack of social support) influence health. Low socioeconomic status is associated with a higher prevalence of overall morbidity, including psychiatric morbidity [3-5], but also a decreased access to high-quality care and a lower consumer demand $[6,7]$. Further, marital status and social

\footnotetext{
*Correspondence: eva.lesen@nhv.se

1 Nordic School of Public Health (NHV), Box 121 33, 40242 Gothenburg, Sweden

support is associated with health and health behaviour [8$10]$.

Health care quality differs between socioeconomic groups, particularly regarding the extent of preventive care, the cost of treatment procedures, and appropriate drug utilisation [6,11-13]. However, research focusing on the association between socioeconomic determinants, psychotropic drugs, and potentially inappropriate psychotropic drugs among the elderly is scarce $[1,14]$. Explicit criteria on potentially inappropriate drugs among the elderly often focus on pharmacological appropriateness, such as choice of drug, dose, drug interactions, duplications, and duration of drug therapy [15]. The Swedish National Board of Health and Welfare (NBHW) has published a list of quality indicators and explicit criteria for measuring inappropriate drug utilisation among the elderly in Sweden [16]. The list 
is based on Swedish recommendations, expert opinions, and internationally published explicit criteria such as Beers' criteria [17].

The introduction of the Swedish Prescribed Drug Register in 2005 [18] enabled linkage of information on drug utilisation and social determinants on an individual level with complete national coverage. This study aimed to analyse whether two socioeconomic determinants - income and marital status - are associated with differences in utilisation of psychotropic drugs and potentially inappropriate psychotropic drugs (PIP) among the elderly in Sweden.

\section{Methods}

\section{Study participants and data sources}

The study participants encompassed all individuals aged 75 years and older on 1 January 2006 in Sweden who had purchased a prescribed psychotropic drug in 2006 ( $\mathrm{n}=$ 384712). Data on dispensed prescription drugs was obtained from the national individual-based Swedish Prescribed Drug Register held at the National Board of Health and Welfare [18]. The register includes all prescribed drugs purchased at Swedish pharmacies, but not drugs utilised in hospitals or purchased over the counter. Information on the participants' age, sex and all purchased prescription drugs (type, amount and date of purchase) was collected. In Sweden, co-payment for reimbursed drugs is independent of income. The maximum co-payment for prescription drugs within the pharmaceutical benefits scheme is SEK 1800 (SEK $1=$ n0.106 on 1 January 2006) per twelve month period (Act 2002:160 on Pharmaceutical Benefits, etc.). Data from the Swedish Prescribed Drug Register was linked to the LISA database (the longitudinal integration database for health insurance and labour market studies; held at Statistics Sweden) via the unique person identification number. Information regarding family disposable income, number of family members, marital status, country of birth and date of death and migration was collected from the LISA database. The project was approved by the regional ethics board in Gothenburg, Sweden (No. 054-07).

Drugs were classified according to the Anatomical Therapeutic Chemical (ATC) classification system [19]. Psychotropic drugs were categorised as follows: any psychotropic (ATC-codes N05 and N06), antipsychotics (N05A), anxiolytics (N05B), hypnotics (N05C), and antidepressants (N06A).

\section{Socioeconomic determinants}

Income was calculated using the square root scale (i.e., family disposable income during 2005 divided by the square root of the number of family members) $[20,21]$. The study participants were categorised into income tertiles to focus on any differences between those with the lowest income compared to those with the highest income. For analyses stratified by sex, this categorisation was per- formed separately for men and women. Marital status on 31 December 2006 was categorised as married, never married, divorced, or widowed. Country of birth was included as a potential confounder and categorised as Sweden, other Nordic countries, other European countries, and outside Europe. The number of unique nonpsychotropic drug substances purchased during the study period was used as a proxy for health care utilisation and comorbidity [22].

\section{Outcome measures}

The number of unique psychotropic drugs purchased during 2006 was dichotomised into three or more vs. less than three psychotropic drugs. Utilisation of three or more psychotropic drugs was considered to reflect an increased exposure to psychotropic drugs. PIP was defined as the utilisation of potentially inappropriate psychotropic substances (PIPS) or potentially inappropriate combinations of psychotropics (PICP), as classified by the NBHW [16]. PIPS was defined as at least one purchase of long-acting benzodiazepines (flunitrazepam, nitrazepam, and diazepam), anticholinergic psychotropics, propiomazine, or triazolam during 2006. PICP was defined as concurrent utilisation of two or more benzodiazepines, two or more psychotropics in the same class (e.g., two or more hypnotics), and two or more anticholinergic psychotropics for a total of 40 days during 2006. The estimation of concurrent drug utilisation has been described previously [23]. Briefly, information on prescribers' dosage instructions is available only as a free text section in the register and is therefore not statistically processable. A review of prescribed daily doses (PDDs) was performed for a random sample of dispensed prescriptions for each substance. Substance-specific population average PDDs were estimated for each psychotropic substance, thus enabling the calculation of theoretical treatment periods based on date of purchase and purchased amount. A detailed description of PIP and associated prevalence rates have been reported previously [23].

\section{Statistical analyses}

A person-year proportion, defined as the proportion of days resident in the country and alive during 2006, was calculated for each individual. For example, the person-year proportion for an individual who died on 26 March 2006 was 0.23 (84/365 days). The person-year proportion was included in the regression models, thereby taking date of death or migration into account. Further, the sum of the person-year proportions was used as the denominator when calculating the prevalence of utilisation of three or more psychotropic drugs and of PIP among the study participants.

Simple and multiple logistic regression analyses were performed for the outcome measures of three or more psychotropic drugs and PIP. The multiple logistic regression models included income or marital status, age, sex, country 
of birth, number of unique nonpsychotropic drug substances purchased during the study period, and the personyear proportion (not included in analyses on marital status). All regression analyses were also performed stratified by age and sex. Due to partially missing data, 366 individuals were excluded from the regression analyses including income. Marital status was recorded at the end of 2006 and was therefore missing for the 40880 individuals who died and the 77 who migrated during the study period. Further, the regression analyses were repeated in a $10 \%$ random sample, since the risk of false positive results increases as the sample size increases.

Simple and multiple Poisson regression analyses were performed for count outcomes (number of psychotropic drugs and number of PIP). The results from the Poisson regression analyses were in agreement with the logistic regression analyses, and are therefore not presented. Chisquare tests were used to compare proportions. The level for statistical significance was 0.05. SAS version 9.1.3 (SAS Institute, NC) was used for data management, and Stata version 10.1 (StataCorp, TX) was used for statistical analyses.

\section{Results}

Table 1 includes the characteristics of the study participants. Individuals with low income had n12003 or less, and those with high income had n15171 or more. Among those who purchased psychotropic drugs, median income was $\mathrm{n} 14937$ for men and n12620 for women. In the entire Swedish population aged 75 years and older $(n=800129)$, median income was $\mathrm{n} 17352$ for men and n13546 for women (source: Statistics Sweden). The proportion of married individuals was lower among psychotropic drug users than in the corresponding entire Swedish population (men $60.8 \%$ [189616/311796], women 27.5\% [133955/487305]; source: Statistics Sweden).

Among the study participants aged $75-79$ years, $22.5 \%$ (25828/114401) had low income; among individuals aged 85 years and older, the corresponding proportion was $43.7 \%$ (65422/149682). Death or migration occurred more commonly among individuals aged 85 years or older compared to $75-79$ years $(16.6 \%$ vs. $5.4 \% ; \mathrm{p}<0.001)$, among those with low compared to high income ( $12.9 \%$ vs. $8.8 \%$; $\mathrm{p}<0.001)$, and among men compared to women $(13.8 \%$ [16610] vs. 9.2\% [24347]; $\mathrm{p}<0.001$ ) (Table 1).

Among elderly psychotropic drug users, $22.1 \%$ (85182) had purchased three or more psychotropic drugs during 2006. Individuals who died or migrated during the study period were more likely to utilise three or more psychotropic drugs compared to those who survived and did not migrate (31.8\% [13019] vs. $21.0 \%$ [72163]; $\mathrm{p}<0.001)$. Older age, female sex, and low income were associated with a higher probability for utilising three or more psychotropic substances (Table 2).
Among individuals with low income, the adjusted odds ratio (aOR) for utilising three or more psychotropic drugs was 1.34 (95\% confidence interval [CI] 1.26-1.43; reference: high income) for men aged 75-79 years, and 0.99 (CI 0.93-1.05) among men aged 85 years or more. For women, the corresponding aORs were 1.23 (CI 1.17-1.28) in the younger age group and 1.03 (CI 0.99-1.07) in the older age group.

Compared to married individuals, the never married, the divorced and the widows/widowers showed a higher probability for utilising three or more psychotropic drugs (Table 3). Men who were never married and divorced women showed the highest probability for utilising three or more psychotropic drugs. The associations were more pronounced among younger rather than older elderly (data not shown).

PIPS were utilised by $36.0 \%$ (138467), and PICP by $12.2 \%$ (46746); $9.0 \%$ (34596) utilised PIPS as well as PICP. Thus, PIP were utilised by $39.2 \%$ (150617). PIP utilisation occurred more commonly among those who died or migrated during the study period compared to those who survived and did not migrate $(42.2 \%$ [17274] vs. $38.8 \%$ [133343]; $\mathrm{p}<0.001$, respectively). Older age and female sex were inversely associated with PIP utilisation, while low income was associated with a higher probability for PIP utilisation (Table 4). The probability for utilising PIPS and PICP, respectively, was higher among individuals with low income (PIPS: aOR 1.14; CI 1.12-1.16; PICP: aOR 1.11; CI 1.08-1.14; reference: high income). The aOR for having both PIPS and PICP was 1.12 (1.09-1.15) among individuals with low income compared to those with high income.

The aOR among men with low income was 1.23 (95\% CI 1.17-1.30; reference: high income) in the younger age group, and 1.14 (1.08-1.20) in the older age group. For women, the corresponding aORs were 1.13 (1.09-1.18) and 1.09 (1.05-1.12), respectively.

Never married and divorced individuals were more likely to utilise PIP compared to married individuals (Table 5). The probability for PIP utilisation was marginally higher among widows/widowers. These associations were more pronounced among the younger than the older elderly (data not shown). The aOR for having both PIPS and PICP was 1.51 (1.44-1.59) among the never married, 1.41 (1.36-1.47) among the divorced, and 1.14 (1.11-1.18) among the widows/widowers, as compared to the married.

The regression analyses performed in the $10 \%$ random sample gave similar results as the original analyses, with two exceptions. The middle income group and the widows/ widowers did not have a statistically significant higher probability for utilisation of PIP in the adjusted analyses ( $p$ $=0.08$ and $\mathrm{p}=0.66$, respectively). 
Table 1: Characteristics of the study participants.

\begin{tabular}{|c|c|c|c|c|}
\hline & Men $(n=120426)$ & Women $(n=264286)$ & Total $(n=384712)$ & $\begin{array}{c}\text { Death/migration, No. } \\
\text { (Row \%) }\end{array}$ \\
\hline \multicolumn{5}{|l|}{ Age } \\
\hline $\begin{array}{l}\text { 75-79 years, No. } \\
(\%)\end{array}$ & $39636(32.9)$ & $74932(28.4)$ & $114568(29.8)$ & $6128(5.4)$ \\
\hline $\begin{array}{l}\text { 80-84 years, No. } \\
(\%)\end{array}$ & $39728(33.0)$ & $80645(30.5)$ & $120373(31.3)$ & $9931(8.3)$ \\
\hline $85+$ years, No. $(\%)$ & $41062(34.1)$ & $108709(41.1)$ & $149771(38.9)$ & $24898(16.6)$ \\
\hline Missing, No. (\%) & $0(0.0)$ & $0(0.0)$ & $0(0.0)$ & $0(0.0)$ \\
\hline \multicolumn{5}{|l|}{ Income $(€)^{*}$} \\
\hline $\begin{array}{l}\text { High income, } \\
\text { median (\%) }\end{array}$ & $21215(33.0)$ & $17457(33.0)$ & $18743(33.0)$ & $11106(8.8)$ \\
\hline $\begin{array}{l}\text { Middle income, } \\
\text { median (\%) }\end{array}$ & $14937(33.8)$ & $12620(33.9)$ & $13126(33.9)$ & $13438(10.3)$ \\
\hline $\begin{array}{l}\text { Low income, } \\
\text { median (\%) }\end{array}$ & $11748(33.1)$ & $10281(33.0)$ & $10632(33.1)$ & $16401(12.9)$ \\
\hline Missing, No. (\%) & $188(0.2)$ & $177(0.1)$ & $365(0.1)$ & $12(3.3)$ \\
\hline \multicolumn{5}{|l|}{ Marital status } \\
\hline Married, No. (\%) & $58376(48.5)$ & $58395(22.1)$ & $116772(30.4)$ & - \\
\hline $\begin{array}{l}\text { Never married, No. } \\
\text { (\%) }\end{array}$ & $8400(7.0)$ & $13350(5.1)$ & $21750(5.7)$ & - \\
\hline Divorced, No. (\%) & $10100(8.4)$ & $25646(9.7)$ & $35746(9.3)$ & - \\
\hline Widowed, No. (\%) & $26814(22.3)$ & $142448(53.9)$ & $169262(44.0)$ & - \\
\hline Missing, No. (\%)† & $16736(13.9)$ & $24446(9.2)$ & $41182(10.7)$ & 40957 (99.5) \\
\hline \multicolumn{5}{|l|}{ Country of birth } \\
\hline Sweden, No. (\%) & $111738(92.8)$ & 241804 (91.5) & $353542(91.9)$ & $38151(10.8)$ \\
\hline $\begin{array}{l}\text { Other Nordic } \\
\text { countries, No. (\%) }\end{array}$ & $3918(3.3)$ & $11852(4.5)$ & $15770(4.1)$ & $1429(9.1)$ \\
\hline Europe, No. (\%) & $3616(3.0)$ & $8232(3.1)$ & $11848(3.1)$ & $1067(9.0)$ \\
\hline $\begin{array}{l}\text { Outside Europe, } \\
\text { No. (\%) }\end{array}$ & $1130(0.9)$ & $2365(0.9)$ & $3495(0.9)$ & $310(8.9)$ \\
\hline Missing, No. (\%) & $24(0.0)$ & $33(0.0)$ & $57(0.0)$ & $0(0.0)$ \\
\hline \multicolumn{5}{|l|}{$\begin{array}{l}\text { Number of unique } \\
\text { drugs }\end{array}$} \\
\hline $1-4$, No. (\%) & $12219(10.1)$ & $26479(10.0)$ & $38698(10.1)$ & $2489(6.4)$ \\
\hline 5-9, No. (\%) & $41504(34.5)$ & $91856(34.8)$ & $133360(34.7)$ & $12040(9.0)$ \\
\hline $10+$, No. (\%) & $66703(55.4)$ & $145951(55.2)$ & $212654(55.3)$ & $26428(12.4)$ \\
\hline Missing, No. (\%) & $0(0.0)$ & $0(0.0)$ & $0(0.0)$ & $0(0.0)$ \\
\hline
\end{tabular}

* Family disposable income for year 2005, adjusted for family size. SEK $1=€ .106$ ( 1 January 2006).

† Marital status was missing for all individuals who died or migrated during $2006(n=40957)$. When these were excluded, marital status was missing for 225 individuals.

\section{Discussion}

The present study showed a higher likelihood for utilising several psychotropics as well as PIP among individuals with low income and among the non-married. While the magnitudes of the higher probabilities were fairly small, they still indicate that socioeconomic determinants are 
Table 2: Age, sex and income and utilisation of three or more psychotropic drugs among the study participants $(n=384346)$.

\begin{tabular}{|c|c|c|c|c|c|}
\hline & $\begin{array}{c}\text { Utilisation of three or } \\
\text { more psychotropics, No./ } \\
\text { Total N (\%)† }\end{array}$ & $\begin{array}{l}\text { Odds Ratio } \\
(95 \% \mathrm{Cl}) \neq\end{array}$ & p-value & $\begin{array}{l}\text { Adjusted Odds Ratio } \\
(95 \% \mathrm{Cl}) \S\end{array}$ & p-value \\
\hline \multicolumn{6}{|l|}{ Age } \\
\hline $75-79$ & $22729 / 111787(20.3)$ & 1 (Reference) & & 1 (Reference) & \\
\hline $80-84$ & $26227 / 115802(22.7)$ & $1.12(1.09-1.14)$ & $<0.001$ & $1.09(1.07-1.11)$ & $<0.001$ \\
\hline $85+$ & $36226 / 137798(26.3)$ & $1.25(1.22-1.27)$ & $<0.001$ & $1.19(1.16-1.21)$ & $<0.001$ \\
\hline \multicolumn{6}{|l|}{ Sex } \\
\hline Men & $24671 / 112602(21.9)$ & 1 (Reference) & & 1 (Reference) & \\
\hline Women & $60511 / 252786(23.9)$ & $1.17(1.15-1.19)$ & $<0.001$ & $1.14(1.12-1.16)$ & $<0.001$ \\
\hline \multicolumn{6}{|l|}{ Income* } \\
\hline High & $25959 / 121784(21.3)$ & 1 (Reference) & & 1 (Reference) & \\
\hline Middle & $29087 / 124009$ (23.5) & $1.11(1.09-1.13)$ & $<0.001$ & $1.06(1.04-1.08)$ & $<0.001$ \\
\hline Low & $30075 / 119233(25.2)$ & $1.19(1.17-1.21)$ & $<0.001$ & $1.12(1.10-1.14)$ & $<0.001$ \\
\hline
\end{tabular}

* Family disposable income for year 2005, adjusted for family size.

† The denominator was adjusted according to the proportion of days the population was resident in the country and alive during 2006

₹ Adjusted for the proportion of days resident in the country and alive during 2006

$\S$ Adjusted for age, sex, income, country of birth, proportion of days resident in the country and alive during 2006, and number of unique nonpsychotropic drug substances purchased during

the study period. 
Table 3: Marital status and utilisation of three or more psychotropic drugs among the study participants $(n=343530)^{*}$.

\begin{tabular}{|c|c|c|c|c|c|}
\hline & $\begin{array}{l}\text { Utilisation of } \\
\text { three or more } \\
\text { psychotropics, } \\
\text { No. (\%) }\end{array}$ & $\begin{array}{l}\text { Odds Ratio } \\
(95 \% \mathrm{Cl})\end{array}$ & p-value & $\begin{array}{l}\text { Adjusted Odds } \\
\text { Ratio }(95 \% \mathrm{Cl}) \dagger\end{array}$ & p-value \\
\hline \multicolumn{6}{|l|}{ Total $(n=343530)$} \\
\hline Married & $21238(18.2)$ & 1 (Reference) & & 1 (Reference) & \\
\hline Never married & $5028(23.1)$ & $1.35(1.31-1.40)$ & $<0.001$ & $1.35(1.30-1.40)$ & $<0.001$ \\
\hline Divorced & 8546 (23.9) & $1.41(1.37-1.45)$ & $<0.001$ & $1.35(1.31-1.39)$ & $<0.001$ \\
\hline Widow/widower & $37332(22.1)$ & $1.27(1.25-1.30)$ & $<0.001$ & $1.17(1.14-1.19)$ & $<0.001$ \\
\hline \multicolumn{6}{|l|}{ Men $(n=103690)$} \\
\hline Married & $10119(17.3)$ & 1 (Reference) & & 1 (Reference) & \\
\hline Never married & $1897(22.6)$ & $1.39(1.32-1.47)$ & $<0.001$ & $1.45(1.37-1.54)$ & $<0.001$ \\
\hline Divorced & 2165 (21.4) & $1.30(1.24-1.37)$ & $<0.001$ & $1.32(1.25-1.39)$ & $<0.001$ \\
\hline Widow/widower & $5489(20.5)$ & $1.23(1.18-1.27)$ & $<0.001$ & $1.19(1.15-1.24)$ & $<0.001$ \\
\hline \multicolumn{6}{|c|}{ Women $(n=239840)$} \\
\hline Married & $11119(19.0)$ & 1 (Reference) & & 1 (Reference) & \\
\hline Never married & $3131(23.5)$ & $1.30(1.25-1.36)$ & $<0.001$ & $1.28(1.23-1.34)$ & $<0.001$ \\
\hline Divorced & $6381(24.9)$ & $1.41(1.34-1.46)$ & $<0.001$ & $1.35(1.30-1.40)$ & $<0.001$ \\
\hline Widow/widower & $31843(22.4)$ & $1.22(1.19-1.25)$ & $<0.001$ & $1.15(1.12-1.18)$ & $<0.001$ \\
\hline
\end{tabular}

† Adjusted for age, sex, country of birth, and number of unique nonpsychotropic drug substances purchased during the study period

* Individuals who died or migrated during 2006 were excluded due to missing information on marital status

associated with differences in utilisation of psychotropic drugs among the elderly. The magnitudes are comparable to a previous Swedish study on inappropriate drug use and education level among elderly [13]. These findings could suggest structural problems in the health care system.

Individuals with low income and the non-married were more likely to utilise three or more psychotropic drugs compared to those with high income and married individuals, respectively. Previous research has shown that the more vulnerable groups have an increased morbidity [4,5]. Information on morbidity was not available for this study; however, our findings could correspond to the ambition of the Swedish health care system to provide health care in relation to individual needs [24].

One of the cornerstones of the Swedish health care is that good health care should be provided for the entire population on equal terms [24]. Consequently, quality in drug treatment should not differ between socioeconomic groups. In this study, individuals with low income were more likely to utilise psychotropic drugs classified as potentially inappropriate by the NBHW compared to those with high income. These findings are consistent with previous studies on socioeconomic determinants and drug utilisation in Sweden [13] and in other countries [11,25-27]. Physicians' choice of drug may be influenced by patients' requests [28]. Since individuals in higher socioeconomic groups generally have increased access to health and drug information [6], they may be more likely to request drugs with a more favourable risk-benefit profile. Previous research has shown that individuals in higher socioeconomic groups are more likely to utilise newly marketed and brand-name drugs $[26,29]$.

Marriage is positively associated with health and health behaviour [8-10]. In a somewhat younger population, divorced women and widowed men had an increased utilisation of psychotropic drugs compared to married or single men and women [14]. Married individuals in our study were less likely to utilise three or more psychotropic drugs as well as PIP compared to non-married individuals. Previous research on the utilisation of potentially inappropriate drugs and marital status or cohabitation is scarce and inconclusive $[11,30]$. The associations between marital status and drug utilisation in this population were more pronounced among men than among women, which may be related to the higher health benefits gained from marriage among men than among women $[9,31]$.

Compared to women, men were less likely to utilise three or more psychotropic substances, but more likely to utilise 
Table 4: Age, sex, and income and utilisation of potentially inappropriate psychotropics among the study participants ( $\mathrm{n}=384346)$.

\begin{tabular}{|c|c|c|c|c|c|}
\hline & PIP, No./Total N (\%)† & $\begin{array}{l}\text { Odds Ratio } \\
(95 \% \mathrm{Cl}) \neq\end{array}$ & p-value & $\begin{array}{l}\text { Adjusted Odds } \\
\text { Ratio }(95 \% \mathrm{CI}) \S\end{array}$ & p-value \\
\hline \multicolumn{6}{|l|}{ Age } \\
\hline $75-79$ & $45788 / 111787$ (41.0) & 1 (Reference) & & 1 (Reference) & \\
\hline $80-84$ & $46658 / 115802$ (40.3) & $0.95(0.93-0.96)$ & $<0.001$ & $0.93(0.91-0.94)$ & $<0.001$ \\
\hline $85+$ & $58171 / 137798$ (42.2) & $0.95(0.93-0.96)$ & $<0.001$ & $0.91(0.90-0.93)$ & $<0.001$ \\
\hline \multicolumn{6}{|l|}{ Sex } \\
\hline Men & $47997 / 112602$ (42.6) & 1 (Reference) & & 1 (Reference) & \\
\hline Women & $102620 / 252786$ (40.6) & $0.96(0.95-0.97)$ & $<0.001$ & $0.94(0.93-0.95)$ & $<0.001$ \\
\hline \multicolumn{6}{|l|}{ Income* } \\
\hline High & $48027 / 121784$ (39.4) & 1 (Reference) & & 1 (Reference) & \\
\hline Middle & $51491 / 124009(41.5)$ & $1.07(1.06-1.09)$ & $<0.001$ & $1.08(1.07-1.10)$ & $<0.001$ \\
\hline Low & $50983 / 119233$ (42.8) & $1.10(1.08-1.12)$ & $<0.001$ & $1.14(1.13-1.16)$ & $<0.001$ \\
\hline $\begin{array}{l}\text { PIP: Potential } \\
\text { * Family disp } \\
\text { † The denom } \\
\text { † Adjusted fo } \\
\text { §Adjusted for } \\
\text { nonpsychotr }\end{array}$ & $\begin{array}{l}\text { priate psychotropic drugs } \\
\text { ome for year } 2005 \text {, adjustec } \\
\text { adjusted for the proportio } \\
\text { ortion of days resident in th } \\
\text { income, country of birth, p } \\
\text { substances purchased duri }\end{array}$ & $\begin{array}{l}\text { mily size. } \\
\text { ys the populatior } \\
\text { ntry and alive dur } \\
\text { on of days resider } \\
\text { study period. }\end{array}$ & $\begin{array}{l}\text { esident in } \\
6 \\
\text { e country }\end{array}$ & $\begin{array}{l}\text { d alive during } 200 \\
\text { 2006, and numb }\end{array}$ & unique \\
\hline
\end{tabular}

PIP. Previous research showed that men were less likely to utilise antidepressants, but more likely to utilise a potentially inappropriate antidepressant [27]. Women generally are more knowledgeable than men about health issues, and physicians describe women as more demanding [32]. This characteristic could increase women's demands regarding quality of care. Further, the oldest old were more likely to utilise several psychotropic drugs, but less likely to utilise PIP as compared the younger elderly. The oldest old may have been prescribed these drugs for a long time and may be unwilling to change to newer drugs. Also, physicians may be more cautious in prescribing these drugs to the oldest old due to the increased risk of adverse events.

Individuals who died during the study period were more likely to utilise three or more psychotropics as well as PIP. This finding could indicate that these individuals had poorer health than the survivors, or that utilisation of these drugs might increase the risk for mortality. However, it is not possible to make any such conclusions based on the data available for this study.

The main strength of this study is its population-based design using national individual-based register data. However, our data does not include drugs utilised in hospitals. The most severe cases may therefore be omitted from the study population, although it is unlikely that individuals are hospitalised during periods long enough to avoid purchase of drugs in pharmacies, as the study period was one year.
Further, no information on the actual use of drugs or indication was available. The cross-sectional design precludes any conclusions regarding causality. Marital status was recorded at the end of the study period; consequently, this information was missing for individuals who died or migrated during the study period. Those individuals were excluded from the regression analyses on marital status and PIP. Since marriage can be related to an increased survival [33], the association between marital status and PIP may be underestimated. Further, large sample sizes may increase the risk of false positive results. However, the regression analyses performed in the $10 \%$ random sample gave similar results as the original analyses.

Cost-related primary nonadherence is associated with income [34]. The Swedish Prescribed Drug Register includes purchased drugs only. Consequently, individuals who choose not to redeem their prescriptions, because they cannot afford them or for other reasons, are not present among the study participants. The restriction of the study participants to those with at least one purchase of a prescribed psychotropic drug may thus underestimate the relationship between income level and drug utilisation.

The classification of PIP was based on international explicit criteria such as Beers' criteria, adapted to Swedish conditions. The scientific documentation is substantial regarding the use of explicit criteria [2]. In some cases, however, drugs classified as potentially inappropriate may 
Table 5: Marital status and utilisation of potentially inappropriate psychotropics among the study participants ( $\mathrm{n}=\mathbf{3 4 3 5 3 0})^{*}$.

\begin{tabular}{|c|c|c|c|c|c|}
\hline & PIP, No. (\%) & $\begin{array}{l}\text { Odds Ratio } \\
(95 \% \mathrm{Cl})\end{array}$ & p-value & $\begin{array}{l}\text { Adjusted Odds } \\
\text { Ratio }(95 \% \mathrm{Cl}) \dagger\end{array}$ & p-value \\
\hline \multicolumn{6}{|c|}{ Total $(n=343530)$} \\
\hline Married & $44501(38.1)$ & 1 (Reference) & & 1 (Reference) & \\
\hline Never married & $9275(42.6)$ & $1.21(1.17-1.24)$ & $<0.001$ & $1.25(1.21-1.29)$ & $<0.001$ \\
\hline Divorced & $15068(42.2)$ & $1.18(1.16-1.21)$ & $<0.001$ & $1.18(1.15-1.21)$ & $<0.001$ \\
\hline Widow/widower & $64433(38.1)$ & $1.00(0.98-1.01)$ & 0.820 & $1.02(1.01-1.04)$ & 0.009 \\
\hline \multicolumn{6}{|l|}{ Men $(n=103690)$} \\
\hline Married & $22303(38.2)$ & 1 (Reference) & & 1 (Reference) & \\
\hline Never married & $3755(44.7)$ & $1.31(1.25-1.37)$ & $<0.001$ & $1.35(1.29-1.41)$ & $<0.001$ \\
\hline Divorced & $4378(43.4)$ & $1.24(1.19-1.29)$ & $<0.001$ & $1.24(1.18-1.29)$ & $<0.001$ \\
\hline Widow/widower & $10420(38.9)$ & $1.03(1.00-1.06)$ & 0.068 & $1.04(1.01-1.07)$ & $<0.001$ \\
\hline \multicolumn{6}{|c|}{ Women $(n=239840)$} \\
\hline Married & $22198(38.0)$ & 1 (Reference) & & 1 (Reference) & \\
\hline Never married & $5520(41.4)$ & $1.15(1.11-1.19)$ & $<0.001$ & $1.18(1.14-1.23)$ & $<0.001$ \\
\hline Divorced & $10690(41.7)$ & $1.17(1.13-1.20)$ & $<0.001$ & $1.15(1.11-1.18)$ & $<0.001$ \\
\hline Widow/widower & $54013(37.9)$ & $1.00(0.98-1.02)$ & 0.691 & $1.01(0.99-1.03)$ & 0.530 \\
\hline
\end{tabular}

PIP: Potentially inappropriate psychotropic drugs

† Adjusted for age, sex, country of birth, and number of unique nonpsychotropic drug substances purchased during the study period

* Individuals who died or migrated during 2006 were excluded due to missing information on marital status

have been appropriately prescribed. This could not be determined, as the Swedish Prescribed Drug Register does not include the necessary information.

\section{Conclusions}

The probability for utilising potentially inappropriate psychotropics, as classified by the NBHW, was higher among individuals with low income and among the non-married. These findings indicate that socioeconomic differences appear to exist in the quality of drug utilisation among elderly.

The differing levels of health knowledge and behaviour among the various socioeconomic groups need to be acknowledged in clinical practice. Efforts to increase good communication between prescribers and patients striving for concordance as well as patient empowerment should be promoted [35]. Further, drug prescribing should not be biased based on socioeconomic characteristics of the patient. Due to the increasing number of elderly in the population, an enhanced knowledge about interventions that effectively increases rational drug use and decreases the impact of socioeconomic determinants in the quality of care among the elderly is essential.
Authors' contributions

All authors were responsible for study concept and design. EL and KA acquired the data. EL and MP were responsible for statistical analyses. All authors interpreted the data. EL drafted the manuscript and all authors contributed with critical revision of the manuscript. All authors read and approved the final manuscript.

\section{Acknowledgements}

This study has received funding from Letterstedtska föreningen and IF:S stiftelse för farmacevtisk forskning. The sponsors had no role in the study design; in the collection, analysis, and interpretation of data; in the writing of the manuscript; and in the decision to submit the article for publication. The researchers were independent from the funders.

\section{Author Details}

1Nordic School of Public Health (NHV), Box 121 33, 40242 Gothenburg Sweden and 2Department of Research and Development, the National Corporation of Swedish Pharmacies, Gothenburg, Sweden

Received: 24 September 2009 Accepted: 9 March 2010

Published: 9 March 2010

\section{References}

1. Mort JR, Aparasu RR: Prescribing potentially inappropriate psychotropic medications to the ambulatory elderly. Arch Intern Med 2000, 160(18):2825-2831.

2. Jano E, Aparasu RR: Healthcare outcomes associated with Beers' criteria: a systematic review. Ann Pharmacother 2007, 41(3):438-447.

3. Banks J, Marmot M, Oldfield Z, Smith JP: Disease and disadvantage in the United States and in England. JAMA 2006, 295(17):2037-2045.

4. Mackenbach JP, Stirbu I, Roskam A-JR, Schaap MM, Menvielle G, Leinsalu $M$, Kunst $A E$, the European Union Working Group on Socioeconomic 
Inequalities in $\mathrm{H}$ : Socioeconomic inequalities in health in 22 European countries. N Eng/ J Med 2008, 358(23):2468-2481.

5. Lorant V, Deliege D, Eaton W, Robert A, Philippot P, Ansseau M: Socioeconomic inequalities in depression: a meta-analysis. Am J Epidemiol 2003, 157(2):98-112

6. Fiscella $K$, Franks $P$, Gold MR, Clancy CM: Inequality in quality: addressing socioeconomic, racial, and ethnic disparities in health care. JAMA 2000, 283(19):2579-2584.

7. Kuno E, Rothbard AB: The effect of income and race on quality of psychiatric care in community mental health centers. Community Ment Health J 2005, 41(5):613-622

8. Williams $K$ : The transition to widowhood and the social regulation of health: consequences for health and health risk behavior. J Gerontol $B$ Psychol Sci Soc Sci 2004, 59(6):S343-349.

9. Umberson D: Gender, marital status and the social control of health behavior. Soc SciMed 1992, 34(8):907-917.

10. Iwashyna TJ, Christakis NA: Marriage, widowhood, and health-care use. Soc Sci Med 2003, 57(11):2137-2147.

11. Fialova D, Topinkova E, Gambassi G, Finne-Soveri H, Jonsson PV, Carpenter I, Schroll M, Onder G, Sorbye LW, Wagner C, et al.: Potentially inappropriate medication use among elderly home care patients in Europe. JAMA 2005, 293(11):1348-1358.

12. Laurier C, Moride Y, Kennedy WA: Health survey data on potentially inappropriate geriatric drug use. Ann Pharmacother 2002, 36(3):404-409.

13. Haider SI, Johnell K, Weitoft GR, Thorslund M, Fastbom J: The influence of educational level on polypharmacy and inappropriate drug use: $\mathrm{A}$ register-based study of more than 600,000 older people. J Am Geriatr Soc 2009, 57(1):62-69.

14. Empereur F, Baumann M, Alla F, Briancon S: Factors associated with the consumption of psychotropic drugs in a cohort of men and women aged 50 and over. J Clin Pharm Ther 2003, 28(1):61-68.

15. Spinewine A, Schmader KE, Barber N, Hughes C, Lapane KL, Swine C, Hanlon JT: Appropriate prescribing in elderly people: how well can it be measured and optimised? Lancet 2007, 370(9582):173-184.

16. National Board of Health and Welfare: Indikatorer för utvärdering av kvaliteten $\mathrm{i}$ äldres läkemedelsanvändning: Socialstyrelsens förslag. [Indicators for evaluation of the quality in drug use among the elderly: Proposal from the National Board of Health and Welfare]. Report number 2003-110-20. Stockholm, Sweden. 2003.

17. Fick DM, Cooper JW, Wade WE, Waller JL, Maclean JR, Beers MH: Updating the Beers criteria for potentially inappropriate medication use in older adults: results of a US consensus panel of experts. Arch Intern Med 2003, 163(22):2716-2724

18. Wettermark B, Hammar N, Fored CM, Leimanis A, Otterblad Olausson P, Bergman U, Persson I, Sundstrom A, Westerholm B, Rosen M: The new Swedish Prescribed Drug Register--opportunities for pharmacoepidemiological research and experience from the first six months. Pharmacoepidemiol Drug Saf 2007, 16(7):726-735.

19. WHO Collaborating Centre for Drug Statistics Methodology: ATC index with DDDs. [http://www.whocc.no].

20. Aaberge R, Björklund $A$, Jäntti $M$, Palme M, Pedersen PJ, Smith N, Wennemo $T$ : Income inequality and income mobility in the Scandinavian countries compared to the United States. Rev Income Wealth 2002, 48(4):443-469.

21. Buhmann B, Rainwater L, Schmaus G, Smeeding TM: Equivalence scales, well-being, inequality, and poverty: Sensitivity estimates across ten countries using the Luxembourg Income Study (LIS) database. Rev Income Wealth 1988, 34(2):115-142.

22. Schneeweiss S, Seeger JD, Maclure M, Wang PS, Avorn J, Glynn RJ Performance of comorbidity scores to control for confounding in epidemiologic studies using claims data. Am J Epidemiol 2001 154(9):854-864

23. Lesén $\mathrm{E}$, Petzold $\mathrm{M}$, Andersson $\mathrm{K}$, Carlsten A: To what extent does the indicator "concurrent use of three or more psychotropic drugs" capture use of potentially inappropriate psychotropics among the elderly? Eur J Clin Pharmacol 2009, 65(6):635-642.

24. Mål för hälso-och sjukvården $2 \S$ [Aims of the health care $2 \S]$. Hälso-och sjukvårdslag (1982:763) [The Swedish health care law (1982:763)]

25. Odubanjo E, Bennett K, Feely J: Influence of socioeconomic status on the quality of prescribing in the elderly -- a population based study. $\mathrm{Br} J$ Clin Pharmacol 2004, 58(5):496-502.
26. Mamdani MM, Tu K, Austin PC, Alter DA: Influence of socioeconomic status on drug selection for the elderly in Canada. Ann Pharmacother 2002, 36(5):804-808

27. Carey IM, De Wilde S, Harris T, Victor C, Richards N, Hilton SR, Cook DG: What factors predict potentially inappropriate primary care prescribing in older people? Analysis of UK primary care patient record database. Drugs Aging 2008, 25(8):693-706.

28. Prosser H, Almond S, Walley T: Influences on GPs' decision to prescribe new drugs-the importance of who says what. Fam Pract 2003, 20(1):61-68

29. Haider SI, Johnell K, Ringback Weitoft G, Thorslund M, Fastbom J: Patient educational level and use of newly marketed drugs: a register-based study of over 600,000 older people. Eur J Clin Pharmacol 2008, 64(12):1215-1222

30. Blalock SJ, Byrd JE, Hansen RA, Yamanis TJ, McMullin K, DeVellis BM, DeVellis RF, Panter AT, Kawata AK, Watson LC, et al.: Factors associated with potentially inappropriate drug utilization in a sample of rural community-dwelling older adults. Am J Geriatr Pharmacother 2005, 3(3):168.

31. Pizzetti P, Manfredini M, Lucchetti E: Variations in late-age mortality by household structure and marital status in Parma, Italy. Ageing Soc 2005, 25(6):305-318

32. Foss C, Sundby J: The construction of the gendered patient: hospital staff's attitudes to female and male patients. Patient Educ Couns 2003, 49(1):45-52.

33. Manzoli L, Villari P, M Pirone G, Boccia A: Marital status and mortality in the elderly: A systematic review and meta-analysis. Soc Sci Med 2007, 64(1):77.

34. Piette JD, Heisler M, Wagner TH: Cost-related medication underuse among chronically ill adults: the treatments people forgo, how often, and who is at risk. Am J Public Health 2004, 94(10):1782-1787.

35. Spinewine A, Swine C, Dhillon S, Franklin BD, Tulkens PM, Wilmotte L, Lorant $\mathrm{V}$ : Appropriateness of use of medicines in elderly inpatients: qualitative study. BMJ 2005, 331(7522):935.

\section{Pre-publication history}

The pre-publication history for this paper can be accessed here: http://www.biomedcentral.com/1471-2458/10/118/prepub

doi: 10.1186/1471-2458-10-118

Cite this article as: Lesén et al., Socioeconomic determinants of psychotropic drug utilisation among elderly: a national population-based cross-sectional study BMC Public Health 2010, 10:118 